\title{
EFFICIENCY AND PRODUCTIVITY OF FIELD CROP FARMS IN LUBLIN PROVINCE IN 2014-2016
}

\author{
Alina Syp ${ }^{1}$, Dr.hab., Assoc. Prof.; Dariusz Osuch ${ }^{2}$, Dr. \\ ${ }^{1}$ Department of Bioeconomy and Systems Analysis, Institute of Soil Science and Plant Cultivation - Sate \\ Research Institute (IUNG-PIB); ${ }^{2}$ Agricultural Accountancy Department, Institute of Agricultural and Food \\ Economics - National Research Institute
}

\begin{abstract}
The aim of this study was to analyse technical efficiency and productivity changes in field crop farms in Lublin province. The assessment of technical, pure and scale efficiency of those farms during 2014-2016 was performed applying non-parametric method of Data Envelopment Analysis (DEA). The Malmquist indices were used to measure the efficiency and productivity changes. The field crop farms based on their economic size were divided into small, medium and large. The study showed that mean technical efficiency of small farms was $83 \%$, medium $-81 \%$ and large - $94 \%$. Technical inefficiency in Lublin region occurred due to pure technical efficiency rather than scale efficiency. It means that inefficient management practices had an impact on farm performance. Therefore, in order to increase competitiveness of Polish crop field farms, it is important to improve management practices. In the studied period the share of farms operating under increasing return to scale decreases with the growth of farm size. The improvement of efficiency of those farms could be achieved by increasing their size. The result indicates that $4 \%$ of small, $14 \%$ of medium and $9 \%$ of large farms were operating under a decreasing scale efficiency, which means that those farms were operating above their optimal scale and could, therefore, increase their efficiency through size reduction. In all the farms, the average annual productivity changes were below 1 . The decrease was mainly due to a technological detrition of 5,6 and $38 \%$ respectively for large, small and medium farms.
\end{abstract}

Key words: technical efficiency, scale efficiency, farm size, field crop farms, Malmaquist indices.

JEL code: D24, Q12, P51

\section{Introduction}

Measuring efficiency has become a key indicator to control and plan production. The Data Envelopment Analysis (DEA) is a non-parametric method for measuring and evaluating performance of peer decision making units (DMUs) compared to the best practice frontier (Toma et al., 2015). Since the first development by Charnes et al. in 1978, the method has been extensively used by researchers in different sectors (Charnes et al., 1978; Sueyoshi et al., 2017). The agriculture is one of the sectors were DEA is frequently used for computing efficiency (Odeck, 2009, Vasiliev et al., 2008, Toma et al., 2017). The DEA has two different orientations: input and output (Charnes et al., 1978). The objective of input orientation model is to minimize inputs, whereas output remains at the same level. In the output oriented model, the objective is to increase outputs with constant input (Malana and Malano, 2006). Toma et al. (2015) stated that input-orientated model is more appropriate for agriculture because it depends on limited inputs. Also, in production system farmers have more control over input rather than output (Syp et al., 2015). Fogarasi and Latruffe (2009) in their research applied an output-oriented model because they assumed it is easier for farmers to modify their final outputs than the amount of inputs. However, Coelli et al. (2005) stated that both models produce similar results and thus the choice of orientation is not important. In addition, DEA allows to evaluate under which returns scale each farm operates: constant (CRS), decreasing (DRS) or increasing (IRS) return to scale.

The aim of the present study was to evaluate the influence of farm size on field crop farms performance in Lublin province in the years 2014-2016. The studies proceeded in three steps. In the first phase, the analysis of efficiency was performed by using technical, pure technical and scale efficiency. Next, farms' scale operation was assessed. Finally, the productivity changes were calculated by applying Malmquist productivity indices. 
The authors have chosen this voivodship for their study because the utilized agricultural area (UAA) of this province accounts for about $10 \%$ of the country's UAA, which places this voivodship on the $3^{\text {rd }}$ place in the ranking of Polish voivodships (CSO, 2017). An average farm size in the analysed province is 9.1 ha, while in Poland -11.5 ha (CSO, 2017). In 2016, it was the second province in terms of the number of applicants submitted for payments, third in the declared area in ha, and payments under the single area payment and greening were of $9.8 \%$ national payments in the frame of Common Agricultural Policy (CAP). Several papers have analysed efficiency and productivity of Polish farms. However, most of them applied simple standard efficiency indicators. According to authors' knowledge, this is the first study in Poland that has estimated the field crop farms efficiency and productivity in Lublin voivodship based on their economic size using DEA models.

DEA uses linear programing to construct the efficient frontier with the best performing observations over the data applied and calculates efficiency measures relative to this frontier (Charnes et al. 1978). The distance from a farm to frontier provides a measure of its efficiency. Efficiency (total, pure and scale) scores get values between 0 and 1 . The fully efficient farm receives score 1 (i.e. on the frontier) and a larger score presents a higher efficiency. The score lower than 1 points out to what level of inputs could be reduced and still produce the same quantity of output. A farm technical efficiency (TE) score was calculated under the assumption of CRS. The TE was divided into two scores: pure technical efficiency (PTE) and scale efficiency (SE). PTE was estimated under VRS and referred to management practices. While SE was the ratio between TE and PTE, and presented the potential scale economies accessible to the farm.

Table 1

Descriptive statistics of the FADN data set applied in DEA: 2014-2016

\begin{tabular}{|c|c|c|c|c|}
\hline \multirow{3}{*}{ No } & \multirow{3}{*}{ General information } & \multicolumn{3}{|c|}{ Farm size } \\
\hline & & Small & Medium & Large \\
\hline & & $(8<=C<25)$ & $(25<=c<100)$ & $(100<=C<500)$ \\
\hline 1. & Number of farms & 102 & 149 & 15 \\
\hline 2. & Total output (PLN) & 69263 & 221485 & 700356 \\
\hline 3. & UAA (ha) & 17.4 & 47.3 & 129.6 \\
\hline 4. & Labour input (h) & 3246 & 4483 & 7274 \\
\hline 5. & Intermediate consumptions (PLN) & 39521 & 125717 & 385781 \\
\hline 6. & Total assets (PLN) & 448605 & 1275581 & 3395123 \\
\hline
\end{tabular}

Notes: PLN - Polish currency. UAA - utilised agricultural area. $h$ - labour input in working hours Source: authors' calculations based on the FADN data

In order to evaluate the role agricultural holding size on the performance of Polish crop field farms, the micro data from Polish Farm Accountancy Data Network (FADN) for the period of 20142016 were used. In the scope of the research, there were only the farms that had collected data in all studied years. Based on EU standard classification of "Type of farming" (TF) to perform the analysis, the authors have chosen the farms classified as field crop farms (TF 1). In those farms, at least $66 \%$ of standard output comes from production of field crops. Next, the set of our farms was divided according to their "Economic size" (ES 6) into three groups: small, medium and large. The standard output (SO) of small farms ranged from 8 to $25 \mathrm{~K}$ Euro $(€)$, the medium - from 25 to 100 $K €$, and the large from more than 100 to less than $500 \mathrm{~K} €$. In the input-oriented DEA model, the authors used four inputs, namely: labour input (SE011) expressed in work hours, total utilised agricultural area (SE025) in hectares, total assets (SE436) and total intermediate consumption 
(SE275). Values of total assets and intermediate consumption were presented in zloty (Polish currency). In the study, the dependent variable was total output (SE131) in zloty.

Descriptive results of small farms efficiency estimates

\begin{tabular}{|c|c|c|c|c|c|}
\hline No & Efficiency scores & Mean & $\begin{array}{l}\text { Standard } \\
\text { deviation }\end{array}$ & Minimum & $\begin{array}{l}\text { Coefficient } \\
\text { of variation }\end{array}$ \\
\hline 1. & \multicolumn{5}{|c|}{ TE } \\
\hline 2. & 2014 & 0.839 & 0.135 & 0.572 & 0.160 \\
\hline 3. & 2015 & 0.824 & 0.136 & 0.494 & 0.165 \\
\hline 4. & 2016 & 0.823 & 0.139 & 0.470 & 0.169 \\
\hline 5. & $2014-2016$ & 0.829 & 0.125 & 0.549 & 0.150 \\
\hline 6. & \multicolumn{5}{|c|}{ PTE } \\
\hline 7. & 2014 & 0.685 & 0.188 & 0.330 & 0.275 \\
\hline 8. & 2015 & 0.625 & 0.195 & 0.260 & 0.313 \\
\hline 9. & 2016 & 0.687 & 0.191 & 0.287 & 0.278 \\
\hline 10. & $2014-2016$ & 0.666 & 0.170 & 0.350 & 0.256 \\
\hline 11. & \multicolumn{5}{|c|}{ SE } \\
\hline 12. & 2014 & 0.815 & 0.169 & 0.330 & 0.207 \\
\hline 13. & 2015 & 0.761 & 0.200 & 0.322 & 0.262 \\
\hline 14. & 2016 & 0.834 & 0.167 & 0.319 & 0.200 \\
\hline 15. & $2014-2016$ & 0.803 & 0.160 & 0.360 & 0.200 \\
\hline
\end{tabular}

Source: authors' calculations based on the FADN data

Descriptive results of medium farms efficiency estimates

\begin{tabular}{|c|c|c|c|c|c|}
\hline No & Efficiency scores & Mean & $\begin{array}{l}\text { Standard } \\
\text { deviation }\end{array}$ & Minimum & $\begin{array}{l}\text { Coefficient } \\
\text { of variation }\end{array}$ \\
\hline 1. & \multicolumn{5}{|c|}{ TE } \\
\hline 2. & 2014 & 0.795 & 0.132 & 0.463 & 0.166 \\
\hline 3. & 2015 & 0.829 & 0.132 & 0.539 & 0.160 \\
\hline 4. & 2016 & 0.799 & 0.135 & 0.533 & 0.169 \\
\hline 5. & $2014-2016$ & 0.807 & 0.134 & 0.463 & 0.166 \\
\hline 6. & \multicolumn{5}{|c|}{ PTE } \\
\hline 7. & 2014 & 0.667 & 0.176 & 0.231 & 0.265 \\
\hline 8. & 2015 & 0.694 & 0.181 & 0.135 & 0.260 \\
\hline 9. & 2016 & 0.654 & 0.180 & 0.299 & 0.276 \\
\hline 10. & $2014-2016$ & 0.672 & 0.180 & 0.135 & 0.268 \\
\hline 11. & \multicolumn{5}{|c|}{ SE } \\
\hline 12. & 2014 & 0.838 & 0.160 & 0.321 & 0.191 \\
\hline 13. & 2015 & 0.837 & 0.160 & 0.152 & 0.191 \\
\hline 14. & 2016 & 0.816 & 0.154 & 0.391 & 0.189 \\
\hline 15. & 2014-2016 & 0.830 & 0.158 & 0.152 & 0.191 \\
\hline
\end{tabular}

Source: authors' calculations based on the FADN data

In addition to the evaluation of farms' technical efficiency, their productivity was assessed using Malmquist productivity indices (Caves et al., 1982). The Malmquist total productivity index (TFP) was divided into: the technological change index (TC), which evaluated shift of the frontier over time, and TE change index which evaluated changes in TE efficiency (Fare et al., 1992). Next, TE change index was decomposed into change of PTE and SE. Indices equal to 1 indicated no change, whereas indices greater or lower than 1 , respectively progress or regress. The average change indices were calculated as geometrical means. The DEAP software was applied to measure the 
efficiency and productivity of field crop farms. Some descriptive statistics for inputs and outputs used are presented in Table 1. Research results and discussion

Descriptive results of large farms efficiency estimates

\begin{tabular}{|c|c|c|c|c|c|}
\hline No & Efficiency scores & Mean & $\begin{array}{l}\text { Standard } \\
\text { deviation }\end{array}$ & Minimum & $\begin{array}{l}\text { Coefficient } \\
\text { of variation }\end{array}$ \\
\hline 1. & \multicolumn{5}{|c|}{ TE } \\
\hline 2. & 2014 & 0.926 & 0.079 & 0.711 & 0.085 \\
\hline 3. & 2015 & 0.943 & 0.097 & 0.732 & 0.102 \\
\hline 4. & 2016 & 0.951 & 0.060 & 0.823 & 0.063 \\
\hline 5. & $2014-2016$ & 0.940 & 0.081 & 0.711 & 0.086 \\
\hline 6. & \multicolumn{5}{|c|}{ PTE } \\
\hline 7. & 2014 & 0.856 & 0.144 & 0.443 & 0.168 \\
\hline 8. & 2015 & 0.866 & 0.144 & 0.544 & 0.166 \\
\hline 9. & 2016 & 0.863 & 0.100 & 0.686 & 0.115 \\
\hline 10. & $2014-2016$ & 0.862 & 0.131 & 0.443 & 0.152 \\
\hline 11. & \multicolumn{5}{|c|}{ SE } \\
\hline 12. & 2014 & 0.919 & 0.112 & 0.623 & 0.121 \\
\hline 13. & 2015 & 0.917 & 0.109 & 0.683 & 0.119 \\
\hline 14. & 2016 & 0.909 & 0.087 & 0.705 & 0.096 \\
\hline 15. & $2014-2016$ & 0.915 & 0.103 & 0.623 & 0.113 \\
\hline
\end{tabular}

Source: authors' calculations based on the FADN data

The proportion of farms according to scale - Constants, Increasing and Decreasing - as an average 2014-2016

\begin{tabular}{|l|l|c|c|c|}
\hline \multirow{2}{*}{ No } & \multicolumn{2}{|c|}{ Description } & \multicolumn{3}{c|}{ Farm size } \\
\cline { 3 - 5 } & & \multicolumn{1}{c|}{ Small } & Medium & Large \\
\cline { 3 - 5 } & & $(8<=€<25)$ & $(25<=€<100)$ & $(100<=€<500)$ \\
\hline 1. & Share of farms operating under: & 9 & 8 & 29 \\
\hline 2. & Constant ( \%) & 86 & 78 & 62 \\
\hline 3. & Increasing (\%) & 4 & 14 & 9 \\
\hline 4. & Decreasing (\%) & & & \multicolumn{2}{c}{} \\
\hline
\end{tabular}

Source: authors' calculations based on the FADN data

Productivity change indices of small farms during 2014-2016

\begin{tabular}{|l|l|c|c|c|c|}
\hline No & \multicolumn{1}{|c|}{ Average productivity change indices } & Mean & Minimum & Maximum & $\begin{array}{c}\text { Standard } \\
\text { deviation }\end{array}$ \\
\hline 1. & TE change index & 0.998 & 0.761 & 1.524 & 0.118 \\
\hline 2. & PTE change index & 1.011 & 0.873 & 1.354 & 0.068 \\
\hline 3. & SE change index & 0.988 & 0.761 & 1.215 & 0.087 \\
\hline 4. & TC change index & 0.992 & 0.771 & 1.244 & 0.062 \\
\hline $\mathbf{5 .}$ & TFP change index & 0.991 & 0.702 & 1.509 & 0.131 \\
\hline
\end{tabular}

The averages of productivity change indices are the geometrical means Source: authors' calculations based on the FADN data 
Productivity change indices of medium farms during 2014-2016

\begin{tabular}{|l|l|c|c|c|c|}
\hline No & \multicolumn{1}{|c|}{ Average productivity change indices } & Mean & Minimum & Maximum & $\begin{array}{c}\text { Standard } \\
\text { deviation }\end{array}$ \\
\hline 1. & TE change index & 1.000 & 0.606 & 1.34050 & 0.126 \\
\hline $\mathbf{2 .}$ & PTE change index & 0.998 & 0.795 & 1.370 & 0.079 \\
\hline $\mathbf{3 .}$ & SE change index & 1.007 & 0.762 & 1.341 & 0.100 \\
\hline 4. & TC change index & 0.955 & 0.690 & 1.217 & 0.085 \\
\hline $\mathbf{5 .}$ & TFP change index & 0.959 & 0.621 & 1.451 & 0.124 \\
\hline
\end{tabular}

The averages of productivity change indices are the geometrical means

Source: authors' calculations based on the FADN data

Productivity change indices of large farms during 2014-2016

Table 8

\begin{tabular}{|l|l|c|c|c|c|}
\hline No & \multicolumn{1}{|c|}{ Average productivity change indices } & Mean & Minimum & Maximum & $\begin{array}{c}\text { Standard } \\
\text { deviation }\end{array}$ \\
\hline 1. & TE change index & 0.990 & 0.773 & 1.111 & 0.079 \\
\hline $\mathbf{2 .}$ & PTE change index & 0.986 & 0.890 & 1.054 & 0.036 \\
\hline $\mathbf{3 .}$ & SE change index & 1.003 & 0.868 & 1.111 & 0.054 \\
\hline 4. & TC change index & 0.993 & 0.862 & 1.064 & 0.056 \\
\hline $\mathbf{5 .}$ & TFP change index & 0.983 & 0.807 & 1.143 & 0.101 \\
\hline
\end{tabular}

The averages of productivity change indices are the geometrical means

Source: authors' calculations based on the FADN data

Tables 2-4 present DEA results for small, medium and large field farms regarding each analysed year and average of 2014-2016. The large farms performed the best in each year and on mean with an average TE of 0.940 (Table 4). These show that the mean potential for input savings among large farm owners was only about $6 \%$. The TE of large farms was the lowest in 2014 and has increased in the subsequent years. The opposite tendency occurred in small farms (Table 2). Despite this fact, the average TE of small farms in the studied period was higher than average TE of medium farms (Table 2-3). The coefficient of variation of TE in large farms range from 0.063 to 0.102 with the average for the analysed period of 0.086 (Table 4 ). The low variation in TE coefficient values show uniform distribution of TE thought the sample. In the other two farm groups, the values of average coefficients of variance TE were twofold compared to large farms but still low because they varied from 0.15 to 0.166 . A different classification compared to TE means was observed for PTE averages in the period of 2014-2016. These values were following: 0.862 , 0.672 and 0.666 respectively for large, medium and small farms. A similar ranking to PTE was observed in SE. The proportion of farms operating under IRS points out that $86 \%$ of small farms tend to operate below their optimal scale (Table 5). The share of farms working under IRS decreased with the growth of farm size. Our results show that $78 \%$ of medium and $62 \%$ of large farms could improve their efficiencies by increasing their size. In the performed analyses, the highest share $(14 \%)$ of farms producing under DRS were found in the medium size farms. These show that the farms were operating above their optimal scale and in fact could rise efficiency by size reduction. In the group of large farms, the number of units operating efficiently amounted to $29 \%$, and was over threefold higher than in small and medium farms. The average Malmquist total productivity (TFP) changes indices as well as the average changes in TFP components for small, medium and large farms in the studied period are presented in Tables 6-8. The average TFP changes were as follows: $0.991,0.959$ and 0.983 respectively for small, medium and large farms. The figures indicate that productivity in all groups of farms decreased. The smallest reduction was recorded for small farms $(0.9 \%)$ and the largest for the medium ones $(4.1 \%)$. Whereas, in large 
farms the decrease amounted to $1.7 \%$. The decline of TFP was mainly due to a technological deterioration $0.7 \%$ in large, $0.8 \%$ in small and $4.5 \%$ in medium farms. Those figures confirmed that technological changes (TC) were negative for all farms in varying degree. By contrast, the medium farms which performed the worst in terms of TFP and TC change, did not recorded any changes in the TE values. For the small and large farms, average TE changes were lower respectively of 0.2 and $1 \%$. The further breakdown of TE change presents that in medium farms, the main source of unchanged technical efficiency indicator was the increase of scale efficiency by $0.7 \%$ because the value of technical improvement decreased by $0.2 \%$. The opposite findings are shown in small farms where efficiency decline depends mainly on SE decreased because of the technical improvement growth by $1.1 \%$. This suggests that owners of these farms improved their farming practices by reducing the input use and scale efficiency. In large farms, progress in SE $(+0.3 \%)$ did not offset the decrease of PTE changes $(-1.4 \%)$.

The first time DEA model was applied to Polish crop farms by Latruffe et al. (2005) to compare TE and PTE between 2000 and 1996. The average UAA of analysed farms corresponded to the average UAA of medium farms from our study. Therefore, the authors compared their results from medium farms to their study, where the input data were similar to FADN data applied in the research. All efficiency scores obtained were higher than calculated by Latruffe et al. (2005). The differences between averages of 2014-2016 and data for 1996 were as follow: 0.15, 0.03 and 0.1, respectively for TE, PTE and SE. Whereas, differences with scores for 2000 amounted to 0.24 for TE and 0.03 for SE. There was no difference between PTE values. The Latruffe et al. (2005) stated the mean reason for the decrease of TE in their study could be the influence of weather conditions, because both years were not very beneficial for agriculture; however, no exceptional crop losses were recorded. In the period of 2014-2016, the weather conditions did not have negative influence on field crop production. In both studies, the SE scores were high because analyses were performed for specialized farms. The lower PTE values in each research in comparison to SE indicate that inefficient are mainly too poor management practices. In both studies, the share of farms operating under the CRS were equal to $78 \%$. Those data suggest that farms were too small and should gain efficiency by increasing size. The share of farms working under DRS were 16 and $14 \%$, respectively for Latruffe et al. (2005) and authors' studies. This implies that those farms were too large. In authors' study, the share of farms operating efficiently was by 2 and $5 \%$ higher than in studies performed for 1996 and 2000 year, respectively. The outcome of this study confirmed that field crop farm size has an impact on farm efficiency. This is in agreement with the research of Latruffe et al. (2005). The results of current analysis reveal that smaller farms tend to produce IRS whereas larger units produce DRS. Those outcomes are in line with Odeck (2009) studies performed for specialized Norwegian grain farms and well known neoclassical production theory.

Rusielik (2010), based on Central Statistical Office data, calculated TE and PTE for Polish agriculture in the period from 2003 to 2006 . The values of TE obtained by him ranged from 0.876 to 0.937 and were slightly higher than TE scores of small and medium field crop farms from our study. Whereas, the TE indicators of large farms were on a similar level. The PTE values computed by Rusielik (2010) ranged from 0.96 to 0.98 and were higher than obtained in our analysis. Kagan (2014) calculated TE, PTE and SE for agricultural enterprises for 2010-2012 in Poland which owned at least 100 ha UAA. Consequently, his scores can be compared with results of large farms. Values obtained by Kagan (2014) range for TE from 0.673 to 0.802 , PTE from 0.717 to 0.832 , and SE 
from 0.831 to 0.957 . The TE and PTE scores were lower than our outcomes, while the SE indicators were similar. Kulawik et al. (2014) calculated TE and PTE for a small group of field farms in Poland in 2007-2011. The average value of TE for the period mentioned above amounted to 0.72 and was lower by $0.09,0.11$ and 0.22 than averages calculated by authors respectively for small, medium and large farms. All the analyses stated above were performed using input-oriented DEA model; however, they varied in the selection of farms and the period of analysis. Moreover, in each of those studies different data were applied. The Latruffe et. al (2005) research is an exception. Similar data input but related to different time span were used by Vasiliev et al. (2008), Ghali et al. (2016) and Latruffe and Desjeux (2016). In Vasilev et al. (2008) studies, the efficiency scores were calculated for Estonian grain farms in which UAA were above 180 ha. Therefore, all the results of this study could be referred to the results of authors' analysis performed for the large farms. The TE of those farms ranged from 0.70 to 0.78 , whereas in Poland varied from 0.93 to 0.95 . However, there were no differences between PTE and SE scores. The share of farms working under IRS recording by Vasilev et al. (2008) was the same as in authors' study. However, in Lublin region the proportion of farms working efficiently amounted to $29 \%$ while in Estonia it was only $15 \%$. Ghali et al. (2016) measured TE and PTE of France field crop farms based on data from 2010. The average UAA of these farms was 148 ha. So, the data from this study could be compared with efficiency of large farms. The average TE of Polish farms in 2014-2016 was higher by 0.29 compared to French farms (0.65). While the difference of PTE value was only 0.05 and standard deviation was the same. Despite both PTE scores were high and there were little differences between them the was a place for improvement of management practices. Latruffe and Desjeux (2016) calculated efficiency indices for 1990-2006 for French field crop farms with average size of 120 ha. So again, the results of this study could be compared with the outcome of large farms in Lublin region. The average TE (0.499) and PTE (0.531) scores were lower than values calculated by authors and researchers mentioned above. However, the SE (0.928) score for these farms was on a similar level as in current research and different studies. The average Malmquist productivity (TFP) changes indices in France and Lublin region were below 1. The decrease of TFP index in France of $2.4 \%$ was due to drop of TE change by $2.5 \%$ and TC by $0.03 \%$. In Poland, the decrease of TFP by $1.1 \%$ was caused by diminished TE by $0.06 \%$ and TC by $0.05 \%$. In the analysed farms, in Lublin region SE change index increased by $0.05 \%$ whereas in France decreased by $0.09 \%$. Those numbers indicate that farmers in Lublin region limit input saving to a greater extent than adopt input saving techniques.

\section{Conclusions, proposals, recommendations}

1) The FADN database allows to apply homogenous variables and indicators across countries and over time to conduct analysis of farms' performance.

2) This study was the first which provided efficiency and productivity estimates for field crop farms in Lublin region during 2014-2016. All scores for this region are in line with those obtained by the previous studies.

3) The arable farms in Lublin region are located on high quality soil which resulted in higher efficiency and productivity scores.

4) The efficiency estimates in Lublin region showed that technical inefficiency is mainly caused by pure technical inefficiency rather than scale efficiency. It means that inefficient management 
practices had a great impact on farm performance. Therefore, in order to increase competitiveness of Polish crop field farms, it is important to improve management practices.

5) All farms during 2014-2016 recorded decrease in productivity change. The medium farms had the highest reduction $(-2.1 \%)$ whereas the small ones had the lowest $(-0.01 \%)$. In all groups of farms, those changes were due to technological regress.

6) This paper contributes to knowledge about the efficiency and productivity of Polish crop field farms and to the literature on efficiency and productivity changes.

\section{Acknowledgements}

The studies have been supported by The National Centre for Research and Development within the project Support for low carbon agriculture - able to adapt to observed climate change in the perspective of 2030 and 2050 (acronym LCAgri).

\section{References:}

1. Caves, D., Christensen, L., Diewert., E. (1982). The Economic Theory of Index Numbers and the Measurement of Input. output. and productivity. Econometrica, 50(6), pp. 1393-1414.

2. Charnes, A., Cooper, W.W., Rhodes, E. (1978). Measuring the Efficiency of Decision Making Units. European Journal of Operational Research, No. 2, pp. 429-444.

3. Coelli, T., Rao, D., O'Donnell, C., Battese, G. (2005). An Introduction to Efficiency and Productivity Analysis. Second Edition. Springer. New York, pp. 1-356.

4. CSO (2017). Statistical Yearbook of the Regions - Poland. Warszawa.

5. Fare, R., Grosskopf, S., Lindgren, B., Roos, P. (1992). Productivity Changes in Swedish Pharmacies 19801989: A Non-parametric Approach. Journal of Productivity Analysis. 3(1-2), pp. 85-101.

6. Fogarasi, J., Latruffe, L. (2009). Technical Efficiency in Dairy Farming: A Comparison of France and Hungry in 2001-2006. Studies in Agricultural Economics, No. 110, pp. 75-84.

7. Kagan, A. (2014). Techniczna i srodowiskowa efektywnosc wielkotowarowych przedsiebiorstw rolnych w Polsce. IERiGZ-PIB Warszawa, pp: 1-153.

8. Kulawik, J. (2014): Doplaty bezposrednie i dotacje budzetowe a finanse oraz funkcjonowanie gospodarstw i przedsiebiorstw rolniczych (4). IERiGZ-PIB Warszawa, No. 120, pp. 1-170.

9. Latruffe, L., Balcombe, K., Davidova, S., Zawalinska, K. (2005). Technical and Scale Efficiency of Crop and Livestock Farms in Poland: Does Specialization Matter? Agricultural Economics, No. 32, pp. 281-296.

10. Latruffe, L., Desjuex, Y. (2016). Common Agricultural Policy Support, Technical Efficiency and Productivity Change in French Agriculture. Review of Agricultural, Food and Environmental Studies, No. 97, pp. 15-28.

11. Malana, M.N., Malano, M.H. (2006). Benchmarking Productive Efficiency of Selected Wheat Areas in Pakistan and India Using Data Envelopment Analysis. Irrigation and drainage, No. 55, pp. 383-394.

12. Odeck, J. (2009). Statistical Precision of DEA and Malmquist Indices: A Bootstrap Application to Norwegian Grain Producers. Omega, No. 37, pp. 1007-1017.

13. Rusielik, R. (2010). Wykorzystanie parametrycznej i nieparametrycznej metody analizy granicznej do pomiaru efektywnosci technicznej rolnictwa - analiza porównawcza. Roczniki Naukowe SERiA, No. 12(1), pp. 174-179.

14. Sueyoshi, T. Yuan, Y. Goto, M. (2017). A Literature Study for DEA Applied to Energy and Environment. Energy Economics, No. 62, pp. 104-124.

15. Syp, A., Faber, A., Borzecka-Walker, M., Osuch, D. (2015). Assessment of Greenhouse Gas Emissions in Winter Wheat Farms Using Data Envelopment Analysis Approach. Polish Journal of Environmental Studies, Vol. 24. No. 5, pp. 2197-2203.

16. Toma, E., Dobre, C., Dona, I., Cofas, E. (2015). DEA Applicability in Assessment of Agriculture Efficiency on Areas with Similar Geographically Patterns. Agriculture and Agricultural Science Procedia, No. 6, pp. 704711.

17. Toma, P., Miglietta, P.P., Zurlini, G., Valente, D., Petrosillo, I. (2017). A Non-parametric Bootstrap-data Envelopment Analysis Approach for Environmental Policy Planning and Management of Agricultural Efficiency in EU countries. Ecological Indicators, No. 83, pp. 132-143.

18. Vasiliev, N., Astover, A., Mõtte, M., Noormets, M., Reintam, E., Roostalu, H. (2008). Efficiency of Estonian Grain Farms in 2000-2004. Agricultural and food science, No. 17, pp. 31-40. 